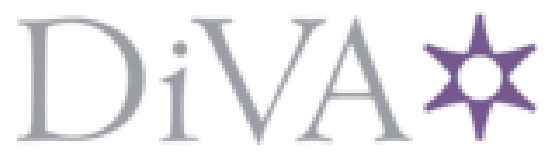

http://www.diva-portal.org

This is the published version of a paper published in Journal of Transportation Safety and Security.

Citation for the original published paper (version of record):

Larcher, M., Forsberg, R., Björnstig, U., Holgersson, A., Solomos, G. (2016)

Effectiveness of finite-element modelling of damage and injuries for explosions inside trains.

Journal of Transportation Safety and Security, 8: 83-100

http://dx.doi.org/10.1080/19439962.2015.1046619

Access to the published version may require subscription.

N.B. When citing this work, cite the original published paper.

Permanent link to this version:

http://urn.kb.se/resolve?urn=urn:nbn:se:umu:diva-117258 


\title{
Effectiveness of finite-element modelling of damage and injuries for explosions inside trains
}

\author{
Martin Larcher ${ }^{a}$, Rebecca Forsberg ${ }^{b}$, Ulf Björnstig ${ }^{b}$, Annelie Holgersson ${ }^{b}$, \\ and George Solomos ${ }^{a}$ \\ ${ }^{a}$ European Commission, Joint Research Centre, European Laboratory for Structural Assessment (IPSC/ \\ ELSA), Ispra, Italy; ${ }^{\mathrm{b} C e n t r e ~ f o r ~ R e s e a r c h ~ a n d ~ D e v e l o p m e n t-D i s a s t e r ~ M e d i c i n e, ~ D e p a r t m e n t ~ o f ~ S u r g i c a l ~ a n d ~}$ \\ Perioperative Sciences, Division of Surgery, Umeå University, Umeå, Sweden
}

\begin{abstract}
The rail-bound sector has become a preferred target of terrorist attacks because of its vulnerability, and the most frequent way to carry out these attacks has been the use of explosive devices. The aim of this study is to investigate the effectiveness of modelling detonation effects inside train carriages using explicit finite element techniques. The numerical simulations consider fluid-structure interaction phenomena and several parametric studies are conducted. Carriage damage and injuries to the passengers are examined. Displacements in the model of the carriage structure do not vary greatly for small changes of the charge size, its location, or by open doors. Changing charge size, the location of the detonation, and door setting, however, had significant impact on the risk of eardrum rupture and fatality. Comparison of the simulation and real life data demonstrate a good agreement between the real and calculated displacements of the carriage, whereas the risk of death and eardrum rupture is slightly higher in the calculations. The model presented can reproduce a reliable actual situation if more parameters that influence injuries of blast waves were considered.
\end{abstract}

\section{KEYWORDS}

blast wave; finite element model; rail bound; risk; security; structural damage

\section{Introduction}

During the years 1970 to 2010 more than 1,000 terrorist attacks were directed at the rail-bound sector, $46 \%$ of which occurred either inside or were directly targeted at a parked or passing train (Strandberg, 2013). Another study showed that there were 78 attacks, with at least 10 deaths and/or 100 injuries, against the rail-bound sector in the period 1970 to 2009. This has resulted in

CONTACT Martin Larcher $\otimes$ martin.larcher@jrc.ec.europa.eu European Commission, Joint Research Centre, European Laboratory for Structural Assessment (IPSC/ELSA), Ispra I-21027, Italy.

Color versions of one or more of the figures in the article can be found online at www.tandfonline.com/utss.

(-) Supplemental data for this article can be accessed on the publisher's website.

(c) 2016 European Union

This is an Open Access article. Non-commercial re-use, distribution, and reproduction in any medium, provided the original work is properly attributed, cited, and is not altered, transformed, or built upon in any way, is permitted. The moral rights of the named author(s) have been asserted.

Published with license by Taylor \& Francis Group, LLC, and The University of Tennessee 
3,049 fatally and 5,435 nonfatally injured (Holgersson \& Björnstig, 2014), even without counting for the major attacks in Madrid (Bolling et al., 2007), London (Lockey et. al., 2005), and Tokyo (Okumura et al., 2005).

Increased focus on transportation security was just one of many effects of the terrorist attacks in the United States on 11 September 2001. The events had a great impact on the way we perceive weaknesses and risks in modern society and highlighted the enormity of problems that needed to be addressed to protect public transportation from terrorism (Johnston \& Nath, 2004; Plant, 2004).

The public transportation system appears to have become a preferred target by terrorists because of the potential for disruption, destruction, and escape of the perpetrator(s), due to its size, openness, accessibility, lack of passenger identification, and the number of people it carries (Jenkins, 2001; Wilson, Jackson, Eisman, Steinberg, \& Riley, 2007). According to terrorism researcher Brian Jenkins (2004), terrorists who target transportation systems are often seeking slaughter; the percentage of terrorist attacks resulting in fatalities has been much higher for attacks on transportation than terrorism in general. It has also been indicated that the frequency and lethality of the attacks have increased over time (Loukaitou-Sideris, Taylor, \& Fink, 2006).

The most frequent way to carry out attacks against the rail-bound sector has been the use of explosive devices (Standberg, 2013), which is also the most deadly compared to other modus operandi such as armed attack, sabotage, and arson (O’Neill, Robinson, \& Ingleton, 2012). Bombs are relatively easy and cheap to construct, with detailed instructions on how to build various forms of explosives readily available online (Weimann, 2004), and can injure enough people to overwhelm the resources in many communities (DePalma, Burris, Champion, \& Hodgson, 2005). Terrorist attacks, such as suicide bombings or explosions, can cause specific issues regarding injury panorama, which the civilian medical community is not accustomed to handle (Frykberg, 2002; Shapira \& Cole, 2006).

Because security measures like those in the aviation transportation system are not applicable nor necessarily effective, it is essential to pay more attention to finding injury preventive and mitigation measures to lessen the consequences of terrorist attacks. Several formulas are available to calculate the risk of injuries to humans by using the blast pressure information. These models are based on very old investigations, some of them from the field of nuclear explosions. This article verifies these formulas for risk determination in case of terrorist attacks by comparing it with a real terrorist attack.

The aim of this study is to investigate the effectiveness of modelling detonations inside train carriages using explicit finite element (FE) techniques against data from the real explosion cases in Madrid 2004. Such a computational tool, which uses explicit FE techniques and considers fluid-structure interaction phenomena, is expected to facilitate the understanding of the involved complex phenomena and to contribute to the reduction of consequences of an explosion in such confined structures. 


\section{Background: Explosions and air blast waves inside trains}

Air blast waves result from a rapid release of energy. The pressure magnitude of an air blast wave arriving at a certain point depends on the distance and size of the charge. The main characteristics of a free-field air blast wave can be summarized as follows (Figure 1): the pressure attains its maximum (peak overpressure $p_{\max }$ ) very fast; the pressure then starts decreasing until it reaches the reference (ambient) pressure (positive phase); it drops below the reference pressure and finally rises to become equal to it. The overpressure impulse (I) is the integral of the overpressure curve over the positive phase, and this also depends on the distance and size of the charge. Either the peak pressure or the impulse has the main influence on a structure or a human body. This can be considered in an analytical approach using a pressure-impulse diagram, which shows the level of damage by combining different values of peak pressure and impulse.

The actual form of the pressure wave depends on the geometrical structure around the charge that thus has implications on the type of injuries inflicted (Almogy et al., 2004). The blast wave transmits forces into the human body and its internal organs, especially to air-filled organs and air-fluid interfaces such as middle ear, lungs, and bowel (DePalma et al., 2005; Phillips \& Zajtchuk, 1991; Wightman \& Gladish, 2001; Wolf, Bebarta, Bonnet, Pons, \& Cantill, 2009). Therefore eardrum rupture is commonly seen (Avidan et al., 2005) as an indicator of exposure of injurious pressure (DePalma et al., 2005). When explosions take place in, for example, a train carriage, which is a confined or enclosed space, the blast wave cannot dissipate as rapidly as in open air. The explosive force is consequently contained, and the maximum pressure is markedly amplified in magnitude due to the confinement (multiple reflections) and the channeling effect in comparison to the free- field explosion (DePalma et al., 2005; Wolf et al., 2009), resulting in a raised incidence of injury and deaths (Arnold, Pinchas, Tsai, \& Smithline, 2004; Chaloner, 2005; Leibovici et al., 1996; Wolf et al., 2009). For example, the incidence of pulmonary primary blast injury may increase threefold in closed-space

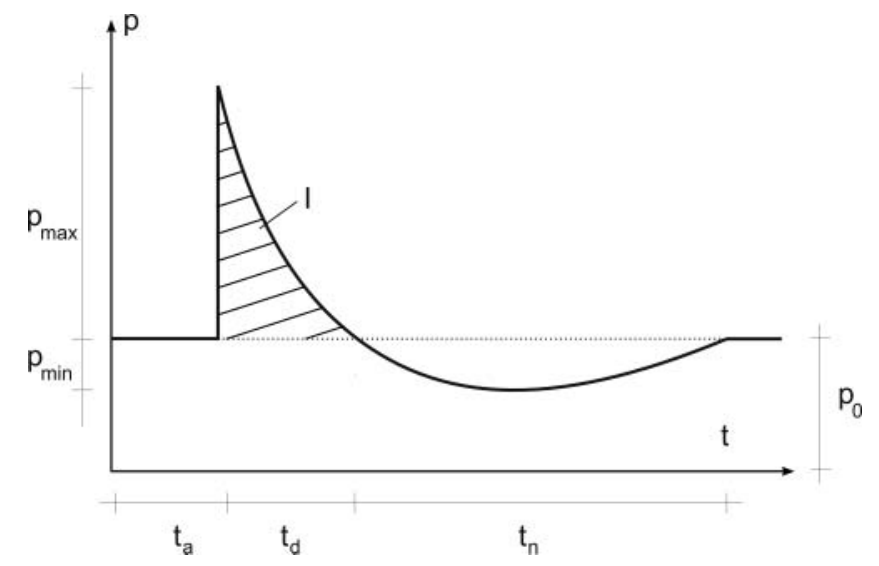

Figure 1. Pressure-time curve for a spherical air blast wave. 
explosions compared to open-air explosions (Wolf et al., 2009). Further, the blast wave's overpressure is amplified when the wave is reflected, for example in the end of the carriage, and the peak pressure can increase as much as eight times due to this (Mayorga, 1997). Passengers close to the ends could therefore be exposed to an enhanced blast overpressure increasing the risk of a blast injury (Arnold et al., 2004; Cooper, Maynard, Cross, \& Hill, 1983; Wolf et al., 2009).

The peak overpressure nevertheless decays rapidly, approximately with the cube of the distance from the explosion. Thus passengers with major disruption of body parts due to the blast effect have usually been closer of the detonated charge (Stein \& Hirshberg, 1999) than those with minor injuries, who have been further away from the channeling of the explosion (Wolf et al., 2009). Further, shadowing and epicenter (tunnel effect) change the channeling of the pressure wave in comparison to an unaffected spherical one. For the situation inside trains the channeling is especially important. At a certain distance from the charge the wave inside the train is one dimensional. The peak pressure decrease may not be as rapid for increasing distance, when obstacles like seats are not considered (Larcher, Casadei, \& Solomos, 2010).

\section{Material and method}

\subsection{The study context}

In the morning of 11 March 2004, ten explosions took place in four commuter trains in Madrid, Spain (Figure 2). Each bomb contained explosive material and a detonator that was connected to the alarm function of a mobile telephone. Fourteen explosive devices had been prepared and put into rucksacks and sports bags, but four bombs never exploded because the timer was set $12 \mathrm{~h}$ too late. The first three bombs exploded when the train had reached the Atocha station. A few seconds later, four bombs exploded at Téllez station. Later, two other explosions shattered the Pozo del Tio Raimundo railway station when the train was starting to leave the station. Lastly, the fourth explosion event took place at a double-decker

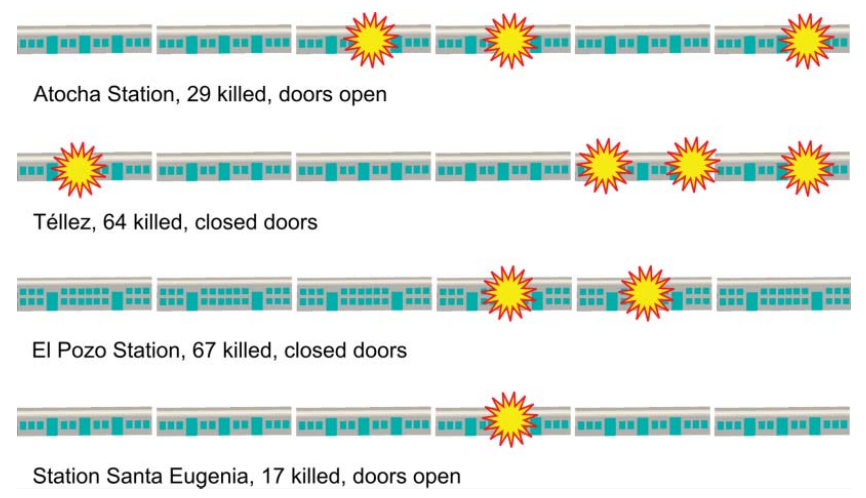

Figure 2. Overview of the ten devices that exploded on the commuter trains in Madrid. Adopted and modified from Bolling et al. (2007). 
train set at the station in Santa Eugenia. Information about the actual number of passengers in each carriage is not available in the public-domain data used, thus plausible estimates are made below.

\subsection{Simulation methods}

All numerical calculations presented have been performed with EUROPLEXUS 2014, an explicit FE code for nonlinear dynamic analysis of fluid-structure systems developed in collaboration between the French Atomic Energy Commission (CEA) and the Joint Research Centre (JRC) of the European Commission. The main focus of EUROPLEXUS is on fluid-structure interaction (FSI) in fast transient dynamics.

There are several methods of numerical modelling that can be used to load a structure with an air blast wave (Larcher \& Casadei, 2010). These methods differ in the number of FEs used and, accordingly, in the computation time. In this article a calculation with full fluid-structure interaction is used, where the charge is represented by a compressed balloon model (Larcher \& Casadei, 2010). Simulations with pressure-time functions are not suitable because reflections, shadowing, and channelling cannot be considered.

Fluid-structure interaction is modelled in EUROPLEXUS using an automatic algorithm (Casadei, 2008), which no longer requires matching nodes for the structure and the fluid. The two meshes are fully independent, and a continuous fluid mesh can be adopted from the beginning. At each time of the computation, a topological search is performed of the fluid nodes, which are reasonably close to the structure. Thanks to optimization of the fluid-structure interaction routines, computation times for the model of the train carriage in Madrid, considered here, are acceptable: with a model of about 460,000 fluid elements and 42,000 structural ones each simulation takes approximately 5 hours on a normal desktop PC.

The simulations are used to assess the effect of several parameters, which are allowed to vary:

- Doors (open/closed)

- Location of the charge (near the door/between the seats)

- Number of passengers $(0 / 100 / 150)$ (The number of passengers per carriage was estimated to approximately 100 in the single ones, and 150 in the double deckers)

- Glass walls (intersections) at the vestibule (Glass walls near the doors to avoid strong air flux when the doors are open) (present/nonpresent)

- Size of the charge $(6 / 9 / 12 \mathrm{~kg})$.

\subsection{Simulation variables}

\subsubsection{Risk model}

The formulation of human injury risk model is based on the work of Ferradás et al. (2008) and Mannan (2005). It uses the peak overpressure $\mathrm{p}_{\max }$ (in $\mathrm{Pa}$ ) and the 
positive impulse I (in Pa s) (Figure 3) inside each fluid FE to determine the probability of eardrum rupture and the probability of death.

Causes of death: Three different causes of death are considered and are determined using the following probit functions:

$$
\begin{gathered}
\text { Head impact }\left(\mathrm{Y}_{1}\right) \quad Y_{1}=5-8.49 \ln \left(\frac{2430}{p_{\max }}+\frac{4 \cdot 10^{8}}{p_{\max } \cdot I}\right) \\
\text { Whole body impact }\left(\mathrm{Y}_{2}\right) \quad Y_{2}=5-2.44 \ln \left(\frac{7380}{p_{\max }}+\frac{1.3 \cdot 10^{9}}{p_{\max } \cdot I}\right) \\
\text { Lung hemorrhage }\left(\mathrm{Y}_{3}\right) \quad Y_{3}=5-5.74 \ln \left(\frac{4.2 \cdot 10^{5}}{p_{\max }}+\frac{1694}{I}\right)
\end{gathered}
$$

Eardrum rupture: The probit function $\mathrm{Y}_{4}$ of eardrum rupture is described using the following equation:

$$
Y_{4}=-12.6+1.524 \ln \left(p_{\max }\right)
$$

The probability of occurrence $R$ (or the percentage of the affected population) of the corresponding injury is next determined for each of the death-related functions using the following equation from Ferradás et al. (2008), which is a good approximation of the relevant cumulative normal distribution:

$$
R_{i}=-3.25 Y_{i}^{3}+48.76 Y_{i}^{2}-206.6 Y_{i}+270.35
$$

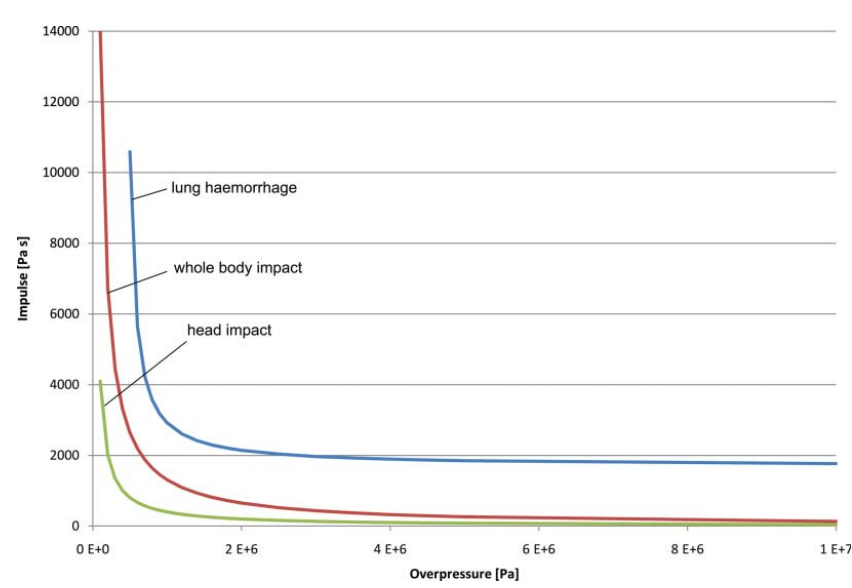

Figure 3. Risk functions inside a pressure-impulse (P-I) diagram: iso-injury (death) curves of $50 \%$ probability. 
The possible interaction among the different causes of death is simplified by considering the maximum of the three associated probabilities:

$$
P_{\text {death }}=\max \left(R_{1}, R_{2}, R_{3}\right)
$$

The risk functions are presented in Figure 3 inside a pressure-impulse diagram for a $50 \%$ probability of death. It can be seen that the risk due to head impact is the dominant one. The $50 \%$ probability of death is reached for the whole body impact and for the lung hemorrhage always for higher pressures or impulses.

Because the peak pressure and the impulse are needed for each element in which the risk should be calculated, a full fluid-structure interaction (FSI) calculation is required for such kind of analysis. It is noted that a probit function for body impact by flying debris has not yet been considered.

\subsubsection{Structure models}

Because detailed drawings were not available, the train has been modelled using the data from the producer (Construcciones y Auxiliar de Ferrocarriles [CAF]). The cross-section of the train carriages, the layout of the windows, and the layout of the interior (seats, etc.) have been approximately reconstructed from images. The simulations have been performed only for non-double-decker trains.

The mechanical system is taken as a frame structure made of IPE80 profiles and a 3-mm thick metal sheet welded on it. The developed pressure wave is influenced by the structure itself but for the carriages typified by the above characteristics it has been found (Larcher et al., 2011) that this influence is relatively small. The glass components are built up using tempered glass with a thickness of $6 \mathrm{~mm}$ because this glass type is mainly used for metro line and suburb train carriages. The opening mechanism of the doors has not been considered in detail. The doors are therefore modelled also from glass to allow for failure. The seats are built from the same material like the structure and have a thickness of $4 \mathrm{~mm}$ and a height of $1.5 \mathrm{~m}$ (Figure 4).

The material properties and the material laws used for the calculations are shown in Table 1. Fully integrated four-node shell elements (Batoz) with five integration points through the thickness are used for all structural elements except for the frame structure where beam elements were used. The floor of the train is considered as nondeformable (fixed boundary).

The failure of the glass (for more details, see Larcher, Solomos, Casadei, \& Gebbeken, 2012) and the steel in the FE simulations is built up using element erosion using a strain-based criterion, that is, elements are eroded from the calculation when a certain strain level is reached. After that, the internal and the external fluid are connected.

In addition to the train interior, passengers are also mechanically modelled to assess their contribution to the absorption the energy of the air blast wave. The rather crude model uses shell elements. A rectangular surface of $1.8 \times 0.4 \mathrm{~m}$ with a 


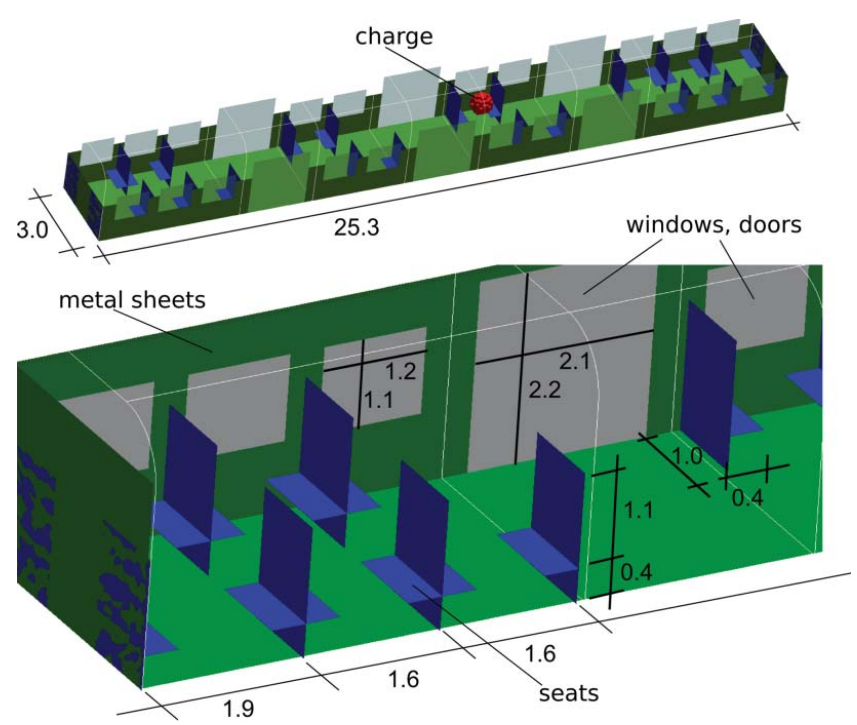

Figure 4. Structure of the train. Metal sheets (only the lower half is shown), windows, seats, charge.

thickness of $0.1 \mathrm{~m}$ is placed orthogonal to the longitudinal axis of the train. With a density of $1400 \mathrm{~kg} / \mathrm{m}^{3}$ the weight of one passenger is $100 \mathrm{~kg}$. The rectangles are not connected to the floor because the friction in case of an air blast wave would be negligible. A simple plastic material law with a Young's modulus of $40 \mathrm{MN} / \mathrm{m}^{2}$ is chosen here, disregarding any interaction of bones, muscles, and so on. This is a very rough approximation by using the force-displacement curve of a thorax compression test because other experimental data, for example, for the tensile behavior are not found in the literature. The model uses a bending strain failure limit of 0.20 .

For the simulations 100 and 150 passengers are randomly allocated through the carriage in a relatively uniform distribution. These numbers represent a normal and a densely populated train, respectively. To speed up the computation, in all calculations the contact effects between the train carriages, the passengers, and the seats are neglected. The influence of such contact on risk estimates is deemed to be very small.

Only one carriage is modelled (Figure 4) and not the entire train. The interactions between the train carriages are supposed to be minimal. The probability that

Table 1. Material laws and parameters for the structure of the metro line carriage.

\begin{tabular}{|c|c|c|c|c|c|}
\hline Material & Material Model & $\begin{array}{l}\text { Density } \\
{\left[\mathrm{kg} / \mathrm{m}^{3}\right]}\end{array}$ & $\begin{array}{c}\text { Young's } \\
\text { Modulus [Pa] }\end{array}$ & $\begin{array}{l}\text { Poisson } \\
\text { Ratio [-] }\end{array}$ & $\begin{array}{c}\text { Elastic } \\
\text { Limit }[\mathrm{Pa}]\end{array}$ \\
\hline Steel & Von Mises & 7800 & $2.1 \mathrm{e} 11$ & 0.333 & $120 \mathrm{e} 6$ \\
\hline $\begin{array}{l}\text { Tempered } \\
\text { glass }\end{array}$ & $\begin{array}{l}\text { Linear elastic, } \\
\text { brittle failure }\end{array}$ & 2500 & $7 e 10$ & 0.23 & $159.6 \mathrm{e} 6$ \\
\hline
\end{tabular}


a blast wave from a reasonable charge destroys the end of a carriage and propagates into the next carriage is small.

\subsubsection{Explosive model}

The blast waves investigated result from the detonation of a solid explosive, which is expressed in terms of a TNT equivalent. The explosive used in the terrorist attack in Madrid was Goma-2 Eco, which is a kind of dynamite, a mixture of nitroglycerine with binding agents such as cellulose, sawdust, or diatomaceous earth. Although the TNT equivalent of nitroglycerine is about 1.6, its mixture with the binding agent has a much lower TNT equivalent. The values in the literature are in the range between 0.8 and 0.9 and depend on the content ratio of nitroglycerine. The model in the simulation does not consider the additional splinters that were added to the charge in the form of nails etc.

The explosion itself is modelled by using the balloon model (Larcher \& Casadei, 2010). A balloon with compressed gas is released in the model that shows a similar pressure history as a detonation from an explosive. The propagation of the blast wave in the air is modelled using eight-node fluid elements with reduced integration. A FSI method connects the blast propagation with the structural elements. Absorbing boundaries of the extremities of the fluid mesh outside the train are used. This implies that the pressure wave can be released through this boundary surfaces without any reflection. The boundary surface consisting of train floor and ground are modelled as rigid bodies.

\section{Results}

\subsection{Displacements of carriage structure}

The displacements of the carriage show mainly the failure mechanism of the structure and indicate the number of fragments flying around. It can be a first impression of the risk inside a train.

The failure mode for the simulation of 9-kg TNT equivalent charge between the seats, closed doors, and 100 passengers is shown in Figure 5 and that for a charge of $12 \mathrm{~kg}$ in Figure 6. It can be seen that the failure of the carriage is similar in both

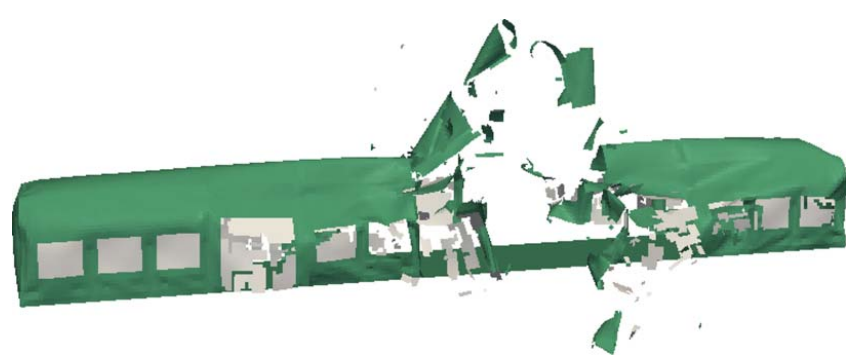

Figure 5. Displacements for 9-kg charge between the seats, closed doors, 100 passengers. 


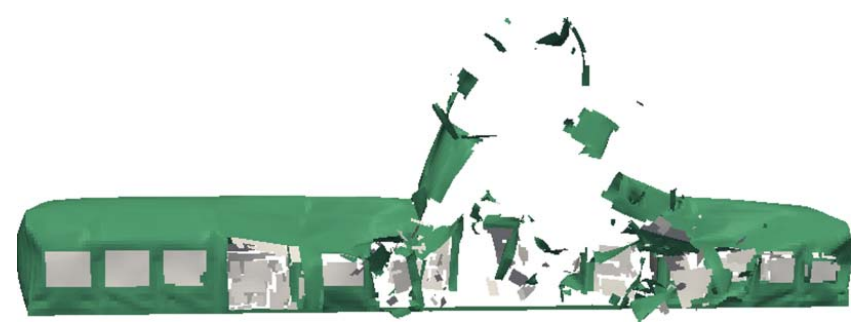

Figure 6. Displacements for 12-kg charge between the seats, closed doors, 100 passengers.

cases. A part with a length of about $5 \mathrm{~m}$ is completely destroyed. Most of the windows are broken. Because of the elongated geometry of the carriage the blast wave from 3D becomes more and more one-dimensional along its propagation (channeling effect). This may result in a strongly deformed and deflected end of the train (Larcher et al., 2011). Additional simulations show that the displacements and the failure do not differ significantly by changing the location of the charge or by considering open doors.

\subsection{Risk calculations}

Risk maps at a horizontal section at a height of $1.5 \mathrm{~m}$ from the carriage floor are given in Figure 7 to Figure 9. All models are created by introducing variations to the main model, which consists of 100 passengers, closed doors, the charge between the seats, and no intersections. The same type of simulation run as above are used and the risk calculation module is activated in EUROPLEXUS during the postprocessing of the results (according to Section 3.3.1). As can be seen, the risk of death is distributed in different ways when different boundary and operation conditions are imposed.

The area with high risk of death (greater than 95\% probability) in the risk maps is measured and is reported in Table 2. By using the ratio of this area with the total

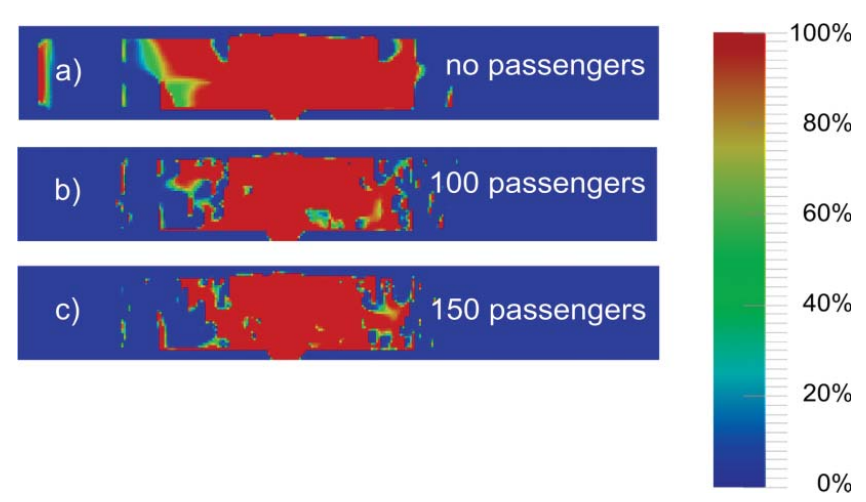

Figure 7. Influence of passengers on risk of death inside the train carriage (9-kg charge between the seats, closed doors): (a) no passengers, (b) 100 passengers, and (c) 150 passengers. 


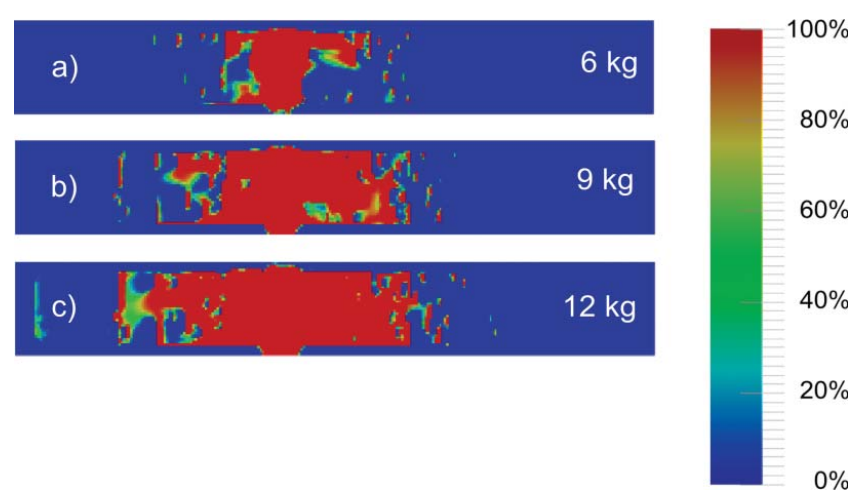

Figure 8. Influence of charge size on risk of death inside the train carriages (100 passengers, charge between the seats, closed doors): (a) $6 \mathrm{~kg}$, (b) $9 \mathrm{~kg}$, and (c) $12 \mathrm{~kg}$.

area of the train $\left(104.13 \mathrm{~m}^{2}\right)$ the number of affected passengers can be calculated under the assumption that the passengers are distributed uniformly. Here 100 passengers are taken into account inside the train carriage. Risk maps concerning the eardrum rupture have also been produced, which due to space limitations have not been shown in the article. Some of their characteristics are, however, reported in Table 2.

It can be observed that the number of deaths is reduced when the doors are open and when the charge is located near a door, which fails faster than the structure. There is also a small protective influence of the intersections near the doors. As expected, the size of the charge has the biggest influence. The number of passengers killed is approximately 23 out of 100 using a charge of 9-kg TNT, and this number is cut in one half when 6-kg TNT equivalent is used. To examine the
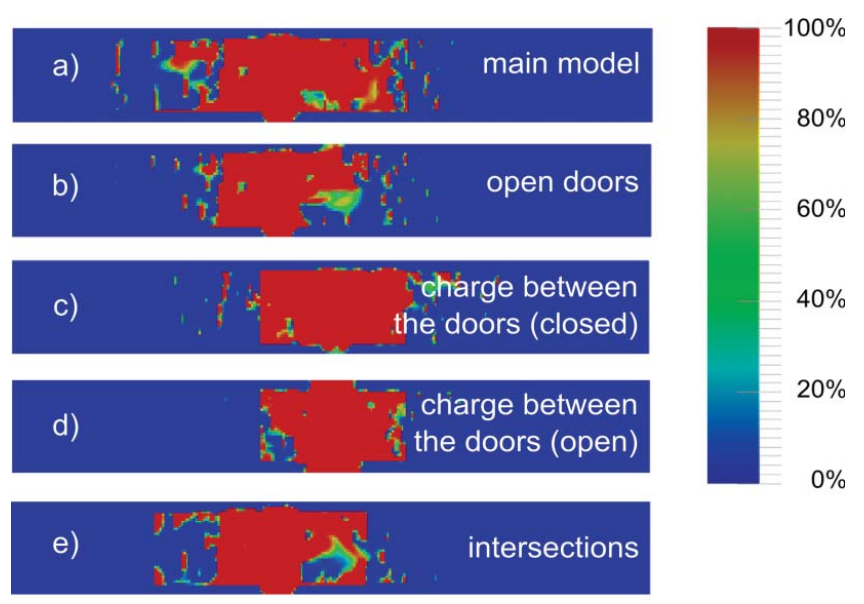

Figure 9. Risk of death inside the train carriages (a) main model: 100 passengers, 9-kg charge between the seats, closed doors, (b) open doors, (c) charge close to the door (closed), (d) charge close to the door (open), and (e) intersections. 
Table 2. Determination of the number of affected passengers (100 passengers).

\begin{tabular}{|c|c|c|c|c|c|}
\hline \multirow[b]{2}{*}{9 kg Charge } & \multicolumn{2}{|c|}{ Deaths } & \multicolumn{3}{|c|}{ Eardrum Rupture } \\
\hline & $\begin{array}{l}\text { Area with } \\
\text { Risk }\left[\mathrm{m}^{2}\right]\end{array}$ & Killed $(n)$ & $\begin{array}{l}\text { Area with } \\
\text { Risk }\left[\mathrm{m}^{2}\right]\end{array}$ & Affected $(n)$ & $\begin{array}{l}\text { Surviving Passengers } \\
\text { with Eardrum Rupture }\end{array}$ \\
\hline Main model & 24.17 & 23.2 & 37.42 & 35.9 & 12.7 \\
\hline Open door & 17.21 & 16.5 & 34.96 & 33.6 & 17.0 \\
\hline Charge close to the door & 20.41 & 19.6 & 33.94 & 32.6 & 13.0 \\
\hline With intersections & 18.29 & 17.6 & 30.39 & 29.2 & 11.6 \\
\hline Without passengers & 30.35 & - & 44.11 & - & - \\
\hline 6-kg charge & 11.36 & 10.9 & 27.41 & 26.3 & 15.4 \\
\hline 12-kg charge & 32.59 & 31.3 & 44.55 & 42.8 & 11.5 \\
\hline
\end{tabular}

influence of the charge on the number of killed passengers additional calculations have been performed, and the results are shown in Figure 10.

The number of surviving passengers with eardrum rupture is almost constant when varying the size of the charge (though the number of deaths is monotonically increasing). There appears to be a zone where the blast pressures are high enough to rupture the eardrum and where the pressure is lower than the lethal pressure, and the size of this zone seems to be nearly constant. Although the number of deaths is reduced by open doors, the number of surviving passengers with eardrum rupture is increased.

\section{Discussion and comparisons}

\subsection{Displacements of carriage structure}

The calculations and simulations are only comparable with three train sets of the terrorist attack in Madrid, schematically shown in Figure 2; as explained earlier, no calculations were performed on the data from the double-decker train set (in El Pozo).

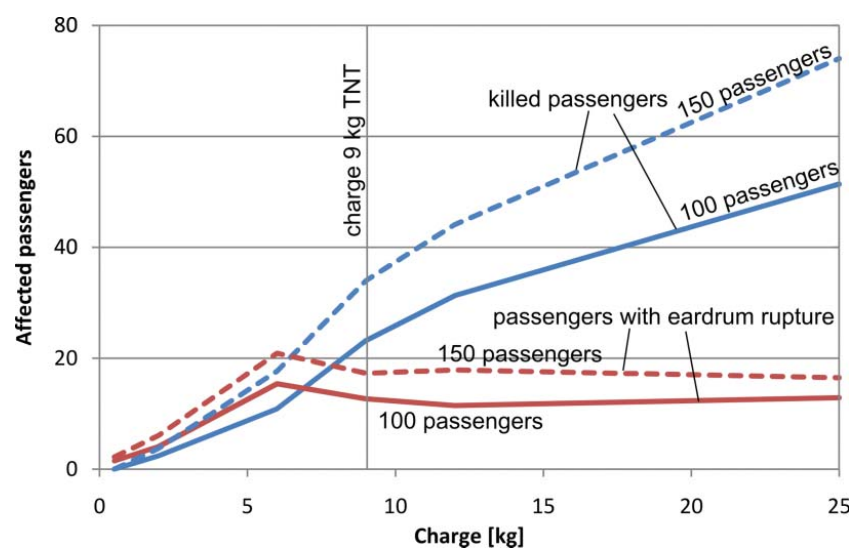

Figure 10. Calculated number of deaths and of eardrum ruptures depending on the size of the charge for 100 and 150 passengers. 


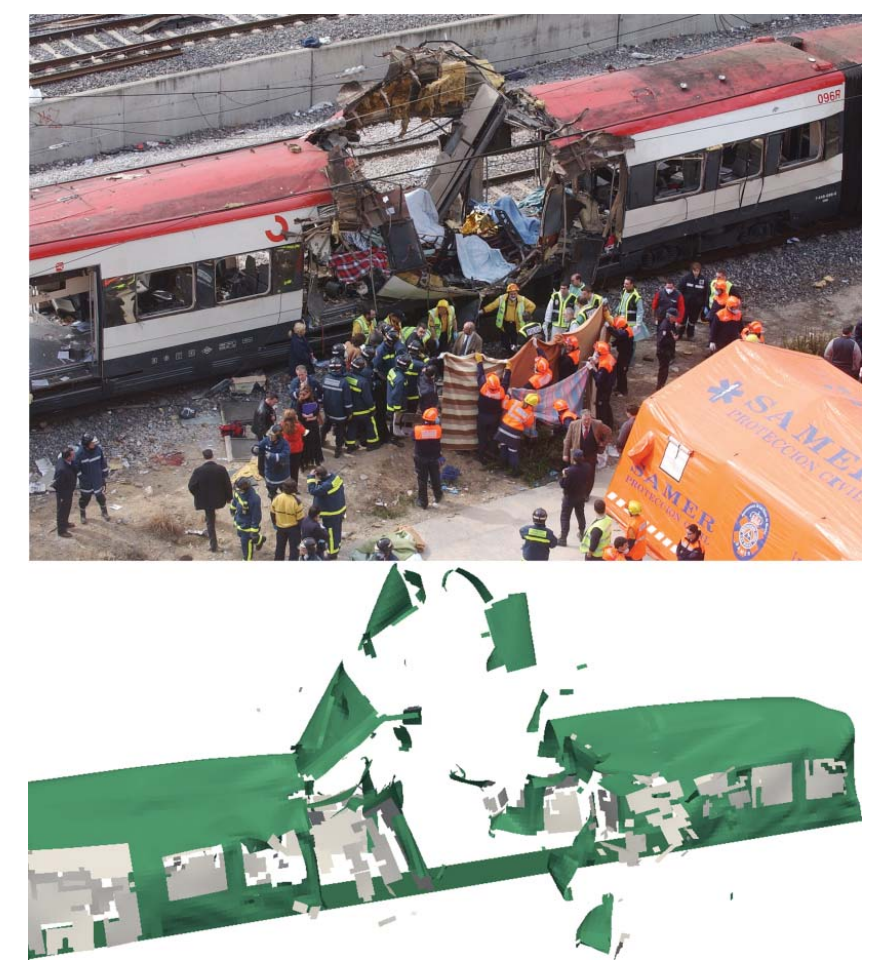

Figure 11. Structural failure of the carriage from one of the explosions at Téllez. Comparison with numerical results. Photograph: Paul White/AP/Scanpix.

When comparing the failure of the carriage from the simulations of 9-kg and $12-\mathrm{kg}$ charge with closed doors (Figure 5 and 6) with pictures from one of the carriages from Téllez (Figure 11), where the doors were also closed, the deformation and failure patterns appear to be similar. This is especially true for the simulation of the 9-kg charge, even though one can sense a slight overestimation of the simulation results from the real event. From Figure 11 it can be estimated that the length of the ruptured zone, where the material is completely ejected, is between 6.0 and $7.5 \mathrm{~m}$. The corresponding length in the simulation with the 9-kg charge is between 5.5 and $6.5 \mathrm{~m}$. O'Neill, Robinson, and Ingleton (2012) rightly pointed out that the heating, ventilation, and air-conditioning (HVAC) equipment of trains have a significant mass and are typically located on the roof of the carriage, which in reality can cause the equipment to fall inside the carriage due to its weight and the negative pressure generated by the blast. Because the structural model does not account for the effect by HVAC equipment, this may explain some of the discrepancies between the simulation and reality. What was essentially demonstrated by the simulations, by using the assumption described in Section 4, was that the structural failure of the carriage did not significantly depend on whether the charge was located between seats or doors, nor whether the doors were open or closed. In the calculations most of the windows broke, as they did in reality in Madrid. As recalled, only one carriage has been modelled and not the entire train set, arguing 
that the separation walls between the train carriages should be stiff enough to practically stop the air blast wave. This assumption is clearly confirmed by the images of the Madrid trains, where it is seen that no damage has been propagated to the adjacent carriages.

\subsection{Risk calculations}

The risk calculations showed that an explosion with open doors results in a smaller number of affected passengers, where all fatalities and survivors with eardrum rupture are included. The location and the size of the charge also had a significant influence on the passengers. If the detonation occurs near fragile structures (e.g., a window), a larger part of the blast wave can be relieved, thus reaching fewer passengers. This is only valid for the near field of the explosion. Several studies (Arnold et al., 2004; Chaloner, 2005; Leviboci et al., 1996; Wolf et al., 2009) have found that the incidence of injury and deaths is raised when explosions take place in a confined or enclosed space as the blast wave cannot dissipate as rapidly as in open air. Almogy and Rivkind (2009) also identified that the extent and severity will depend on factors such as the explosive power of the device, distance of the victim from the site of detonation, quantity and mass of fragments, and attack setting. The simulations show that a charge of $6-\mathrm{kg}$ TNT instead of $9 \mathrm{~kg}$, results in $20 \%$ less fatalities, whereas a charge of $12-\mathrm{kg}$ TNT results in $30 \%$ more fatalities.

All kinds of internal structures, like seats, intersections, and doors, significantly reduced the spread of the blast wave, as did the mass of the passengers themselves. With respect to the case of 150 passengers inside the train, the zone of high lethal risk in the case of an empty carriage is increased by about 30\% (where, of course, there are no affected passengers).

Detailed information about the location of the dead or injured passengers was not available for the terrorist attacks in Madrid, and this is the reason that average numbers per explosion are used instead. In the Atocha station, three explosions took place and the number of killed passengers per explosion was 9.7. In Atocha the doors were open and surveillance videos showed that passengers had already exited the train, which explains the low number of fatalities at this station. In Santa Eugenia (closed doors) 17 passengers were killed from a single explosion. The number of killed passengers per explosion in Telléz (closed doors) was 16. The undetonated bomb that was found by the police contained 10.2-kg Goma-2 explosive, corresponding a TNT equivalent of $9 \mathrm{~kg}$. Whether the other bombs contained roughly the same amount of explosive is not known, but it is plausible to assume that the numerical simulations with a charge of 9-kg TNT equivalent and with 100 passengers should adequately represent the blast scenario and the associated risk (Table 2).

Turégano-Fuentes, Pérez-Diaz, et al. (2008) and Turégano-Fuentes, Cabaoussoux, et al. (2008) have gathered data on 512 casualties assessed and 
found out that almost 250 suffered eardrum perforation, which in $60 \%$ of the cases were bilateral. This is approximately 25 passengers with eardrum perforation per explosion on the average. This real number of passengers in Madrid with eardrum rupture compares well with the simulations prediction, which was in the range of 15 to 20 .

\subsection{Methodological consideration}

In reality the distribution of the passengers is not constant because most of them are standing near the entrances, and there are probably fewer passengers per area around the seats. This nonuniform distribution can be simulated by assigning a higher influence factor to zones with larger passenger density. This was done for one of the simulations, but the resulting influence was small. The zone with high risk always contains an entrance and a part with seats so that the density of passengers inside this zone is quite similar.

Additionally, one should keep in mind that the model does not consider all injuries that can be the cause of death, as, for example, secondary blast injuries due to ejected fragments or tertiary blast effects. The risk due to flying fragments like glass splinters often also result in injuries and fatalities. The effect of these fragments is not yet included in the risk model, but further investigations will be done to incorporate it.

If such variables were computed as well, the accuracy between the model and reality could possibly improve. This is an interesting task for future research. On the other hand most of these injuries involve soft tissue and skeletal injuries that are not life threatening (Frykberg, 2009). The effect of quaternary blast injury in terms of structural collapse in Madrid, as the pictures indicate, was not so large; this mechanism clearly would have increased the level of injury and death according to Frykberg (2009).

\subsection{Implications}

Because it is not realistic to construct and replace all existing train sets with bombproof ones, a workable strategy could be to modify the existing train carriages, to reduce the effect of explosions on passengers and infrastructure.

As seen, reduction of the pressure levels, without changing the complete structure of the train, can be achieved, for example, by intersections of about $0.8-\mathrm{m}$ width, built from laminated glass, placed near the door (Figure 12). The displacements and structural failure in the model using the intersections are similar to those without this kind of internal structure. However, the number of deaths (for 100 passengers) in the simulations is reduced in this case by $25 \%$.

The location of the detonation also has a significant influence. If it occurs near frangible structures, a part of the blast wave can be relieved (only valid for the near field of the explosion). Consequently the possibility to employ structures that can reduce the blast wave should be explored. Windows can also act locally as venting 


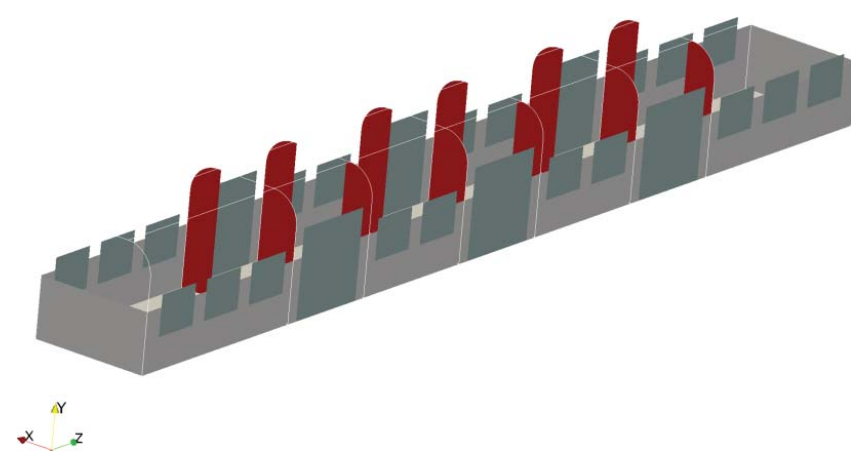

Figure 12. Location of the intersections.

areas because they are open after the glass failure. However, venting areas do not have a significant influence if they are distant from the charge because the blast soon takes a one-dimensional form due to channelling effects, as shown by Larcher et al. (2010).

\section{Conclusions}

A mechanical model based on explicit FE calculations has been employed for assessing explosion effects inside train carriages. Estimates of the structural behavior and of the risk of human injuries have been obtained, and a verification of the model has been attempted using relative data from the Madrid train terrorist attacks.

The comparison between the crude data of the real events and simulations results shows that the model presented can reasonably reproduce the actual situation with respect to the structural failure of the train carriage. The risk model used also performs satisfactorily, though there are still several parameters that influence the lethal effects of blast waves that need to be considered. An improved and validated such FE model can be used to provide information on how to design rail carriages capable of mitigating the effects of a bomb attack, as well as to calculate a posteriori possible outcomes, given an attack.

\section{Funding}

The authors would like to show gratitude to the Swedish National Board of Health and Welfare for financial support.

\section{References}

Almogy, G., Belzberg, H., Minz, Y., Pikarsky, A., Zamir, G., \& Rivkind, A. (2004). Suicide bombing attacks. Annals of Surgery, 239, 295-303.

Almogy, G., \& Rivkind, A.-I. (2009). Penetrating injury in terror medicine. In S.-C. Shapira, J.-S. Hammond, \& L.-A. Cole (Eds.), Essentials of terror medicine. New York: Springer. pp. 271-285. 
Arnold, J., Pinchas, H., Tsai, M., \& Smithline, H. (2004). Mass casualty terrorism bombings: A comparison of outcomes by bombing type. Annals of Emergency Medicine, 43, 263-273.

Avidan, V., Hersch, M., Armon, Y., Spira, R., Aharoni, D., Reissman, P., \& Schecter, W. (2005). Blast lung injury: clinical manifestations, treatment, and outcome. American Journal of Surgery, 190, 945-950.

Bolling, R., Ehrlin, Y., Forsberg, R., Rüter, A., Soest, V., Vikström, T., Örtenwall, P., \& Brändström, H. (2007). KAMEDO Report No. 90: Terrorist attacks in Madrid, Spain, 2004. Prehospital and Disaster Medicine, 22(3), 252-257.

Casadei, F. (2008, June/July). Fast transient fluid-structure interaction with failure and fragmentation. Paper presented at the 8th World Congress on Computational Mechanics, Venice, Italy.

Chaloner E. (2005). Blast injury in enclosed spaces. BMJ, 331, 119-120.

Cooper, G., Maynard, R., Cross, N., \& Hill, J. (1983). Casualties from terrorist bombings. Journal of Trauma, 23, 955-967.

DePalma, R. G., Burris, D., Champion, H. R., \& Hodgson, M. (2005). Blast injuries. New England Journal of Medicine, 352, 335-342.

EUROPLEXUS. (2014). EUROPLEXUS Webpage. Retrieved from http://www-epx.cea.fr/

Ferradás, González E., Díaz Alonso, F., Doval Miñarro, M, Miñana Aznar, A., Ruiz Gimeno, J., \& Sánchez Pérez, J. F. (2008). Consequence analysis by means of characteristic curves to determine the damage to humans from bursting spherical vessels. Process Safety and Environmental Protection, 86, 121-129.

Frykberg, E. R. (2002). Medical management of disasters and mass casualties from terrorist bombing: How can we cope? Journal of Trauma, 53, 201-212.

Frykberg, E. R. (2009). Explosions and blast injury. In S.-C. Shapira, J.-S. Hammond, \& L.-A. Cole (Eds.), Essentials of terror medicine (pp. 171-193). New York: Springer.

Holgersson, A., \& Björnstig, U. (2014). Mass-casualty attacks om public transportation. Journal of Transportation Security, 7, 1-16. doi:10.10077s12198-013-0125-Z

Jenkins, B. (2001). Protecting public surface transportation against terrorism and serious crime: An executive overview. San José: Mineta Transportation Institute

Jenkins, B. (2004). Terrorism and the security of public surface transportation. Santa Monica, CA: RAND Corporation.

Johnston, V., \& Nath, A. (2004). Introduction: Terrorism and transportation security. Review of Policy Research, 21(3), 255-261.

Larcher, M., \& Casadei, F. (2010). Explosions in complex geometries - A comparison of several approaches. International Journal of Protective Structures, 1(2), 169-195.

Larcher, M., Casadei, F., Giannopoulos, G., Solomos, G., Planchet, J. L., \& Rochefrette, A. (2011). Determination of the risk due to explosions in railway systems. Proceedings of the Institution of Mechanical Engineers, Part F, Journal of Rail and Rapid Transit, 225(4), 373382.

Larcher, M., Casadei, F., \& Solomos, G. (2010). Influence of venting areas on the air blast pressure inside tubular structures like railway carriages. Journal of Hazardous Materials, 183(1/ 3), 839-846.

Larcher, M., Solomos, G., Casadei, F., \& Gebbeken, N. (2012). Experimental and numerical investigations of laminated glass subjected to blast loading. International Journal of Impact Engineering, 39, 42-50.

Leibovici, D., Gofrit, O. N., Stein, M., Shapira, S.C., Noga, Y., Heruti, R. J., \& Shemer, J. (1996). Blast injuries: Bus versus open-air bombings - A comparative study of injuries in survivors of open-air versus confined space explosions. Journal of Trauma - Injury, Infection and Critical Care, 41(6), 1030-1035. 
Lockey, D., MacKenzie, R., Redhead, J., Wise, D., Harris, T., Weaver, A., Hines, K., \& Davies, G. (2005). London bombings July 2005: Immediate pre-hospital medical response. Resuscitation, 66(2), ix-xii.

Loukaitou-Sideris, A., Taylor, B. D., \& Fink, C. N. Y. (2006). Rail transit security in an international context: Lessons from four cities. Urban Affairs Review, 41(6), 727-748.

Mannan, S. (2005). Lee's loss prevention in the process industries; Vol. 2: Hazard identification, assessment and control. Amsterdam, The Netherlands: Elsevier.

Mayorga, M. A. (1997). The pathology of primary blast overpressure injury. Toxicology, 121,1728.

Okumura, T., Hisaoka, T., Yamada, A., Naito, T., Isonuma, H., Okumura, S., \& Suzuki, K. (2005). The Tokyo subway sarin attack - lessons learned. Toxicology and Applied Pharmacology, 207, 471-476.

O’Neill, C., Robinson, A., \& Ingleton, S. (2012). Mitigating the effects of firebombs and blast attacks on metro systems. Procedia - Social and Behavioral Sciences, 48, 3518-3517.

Phillips, Y. Y., \& Zajtchuk, R. (1991). The management of primary blast injury. In R. F. Bellamy \& R. Zajtchuk (Eds.), The textbook of military medicine-conventional warfare: ballistic, blast, and burn injuries (pp. 295-335). Washington, DC: Department of the Army, Office of the Surgeon General.

Plant, J. (2004). Terrorism and the railroads: Redefining security in the wake of 9/11. Review of Policy Research, 21(3), 293-305.

Shapira, S. C., \& Cole, L. A. (2006). Terror medicine: Birth of a discipline. Journal of Homeland Security and Emergency Management, 3(2), Article 9. doi:10.2202/1547-7355.1247.

Standberg, V. (2013). Rail bound traffic - A prime target for contemporary terrorist attacks? Journal of Transportation Security, 6(3), 271-286.

Stein, M., \& Hirshberg, A. (1999). Medical consequences of terrorism. The conventional weapon threat. Surgical Clinics of North America, 79, 1537-1552.

Turégano-Fuentes, F., Caba-Doussoux, P., Jover-Navalón, J. M., Martín-Pérez, E., FernándezLuengas, D, Díez-Valladares, L., Pérez-Días, D., Yuste-García, P., Guadalajara Labajo, H., Ríos-Blanco, R., Hernando-Trancho, F, García-Moreno Nisa, F., Sanz-Sánchez, M., GarzíaFuentes, C., Martínez-Virto, A, León-Baltasar, J., \& Vazquez-Estévez, J. (2008). Injury patterns from major urban terrorist bombings in trains: The Madrid experience. World Journal of Surgery, 32, 1168-1175.

Turégano-Fuentes, F., Pérez-Diaz, D., Sanz- Sánchez, M., \& Alonso, J. O. (2008). Overall assessment of the response to terrorist bombings in trains, Madrid, 11 March 2004. European Journal of Trauma and Emergency Surgery, 34, 433-441.

Weimann, G. (2004). www.terror.net: How modern terrorism uses the Internet. (Special Report 116). United States Institute of Peace. Retrieved from http://www.usip.org/sites/default/files/ sr116.pdf

Wightman, J. M., \& Gladish, S. L. (2001). Explosions and blast injuries. Annals of Emergency Medicine, 37, 664-678.

Wilson, J., Jackson, B., Eisman, M., Steinberg, P., \& Riley, J. (2007). Securing Americás passenger-rail systems. Santa Monica, CA: RAND Corporation.

Wolf, S. J., Bebarta, V. S., Bonnett, C. J., Pons, P., \& Cantill, S. (2009). Blast injuries. Lancet, 374, 405-415. 